Article

\title{
Enthalpies of Combustion and Formation of Severely Crowded Methyl-Substituted 1,3-dioxanes. The Magnitudes of 2,4- and 4,6-diaxial Me,Me-Interactions and the Chair-2,5-twist Energy Difference
}

\author{
Kalevi Pihlaja ${ }^{1, *(\mathbb{C})}$, Henri Kivelä ${ }^{1, * \mathbb{C}}$, Pirjo Vainiotalo ${ }^{2}$ and William V. Steele ${ }^{3}$ \\ 1 Department of Chemistry, University of Turku, FI-20500 Turku, Finland \\ 2 Department of Chemistry, University of Joensuu, FI-80100 Joensuu, Finland; pirjo.vainiotalo@joensuu.fi \\ 3 Department of Chemistry, University of Stirling, Stirling FK9 4LA, Scotland, UK; wsteele@utk.edu \\ * Correspondence: kpihlaja@utu.fi (K.P.); hemiki@utu.fi (H.K.); Tel.: +358-505532470 (K.P.)
}

Received: 25 May 2020; Accepted: 11 June 2020; Published: 15 June 2020

\begin{abstract}
Enthalpies of combustion of 2,2-trans-4,6- (1) and 4,4,6,6-tetramethyl- (2) and 2,4,4,6,6- (3) and 2,2,4,4,6-pentamethyl-1,3-dioxanes (4) were determined to estimate their enthalpies of formation in the gas phase. By comparing the latter with the corresponding enthalpies estimated based on the various bond-bond interactions allowed to determine the chair-2,5-twist energy difference $\left(\Delta H_{\mathrm{CT}}=\right.$ $29.8 \mathrm{~kJ} \mathrm{~mol}^{-1}$ ) for 1 since $\mathrm{C}-13$ shift correlations indicate that it escapes to the 2,5-twist form where the 2-methyl groups are isoclinal and 4- and 6-methyl groups pseudoequatorial to avoid syn-axial interactions. Compounds 2 and 3 in turn give the values 21.0 and $21.6 \mathrm{~kJ} \mathrm{~mol}^{-1}$ for the 4,6-diaxial Me,Me-interaction. Finally compound 4, which retains the chair conformation to avoid pseudoaxial interactions in the twist forms gives the value $19.5 \mathrm{~kJ} \mathrm{~mol}^{-1}$ for the 2,4-diaxial Me,Me-interaction indicating that its chair form appears to be somewhat deformed.
\end{abstract}

Keywords: crowded 1,3-dioxanes; enthalpies of combustion; enthalpies of formation; chair-2,5-twist energy difference; syn-axial Me,Me-interactions

\section{Introduction}

We have thoroughly studied the conformations of various heterocycles [1], especially those of methyl-substituted 1,3-dioxanes [1] (pp. 91-96). Our oxygen-containing compounds allowed us, together with the literature data [2], to assemble sets of bond-bond interactions which together with the enthalpies of formation of gaseous atoms and bond energies allow the estimation of enthalpies of formation. The latter do not cover e.g., the 2,4- and 4,6-diaxial Me,Me-interactions present in 2,2,4,4,6-pentamethyl- (4) or 4,4,6,6-tetra- (2) and 2,4,4,6,6- pentamethyl-1,3-dioxanes (3) and e.g., the chair-2,5-twist energy difference in 1,3-dioxanes. This is why we have determined earlier the enthalpies of combustion and formation of gaseous 2,2-trans-4,6-tetramethyl-1,3-dioxane [3,4] (1) which is known, based on C-13 chemical shift correlations, to attain a 2,5-twist form [1,5] and determine those of $\mathbf{2}-\mathbf{4}$ which, again based on C-13 chemical shift correlations [1,5], seem to retain the chair conformation $[1,4]$. 


\section{Results}

\subsection{Preparation of the Studied Compounds}

\subsubsection{Starting Materials}

- 2-Methyl-2,4-pentanediol was a commercial product from Fluka AG (Buchs, Switzerland).

- 2,4-Dimethyl-2,4-pentanediol was prepared with Grignard reaction from ethyl $\beta$-methyl, $\beta$ hydroxybutyrate and methyliodide [6]. Its boiling point was $363-365 \mathrm{~K}$ at $1.7 \mathrm{kPa}$.

\subsubsection{1,3-Dioxanes}

- 4,4,6,6-tetramethyl-1,3-dioxane (2) was prepared with the method developed by Rondestvedt [7] from 2,4-dimethyl-2,4-pentanediol and paraformaldehyde (formaldehyde polymer) in dichloromethane using $p$-toluenesulfonic acid as catalyst. After the distillation, the product was allowed to stand on saturated sodium bisulfite solution until all unreacted aldehyde was removed. Final purification was carried out on a Perkin Elmer F 21 preparative gas chromatograph using a $4.5 \mathrm{~m}$ steel column including 20\% Carbowax 20M as the liquid phase and Chromosorb G (60/80 mesh) as the solid phase. The boiling point was $349 \mathrm{~K}$ at $6.9 \mathrm{kPa}$ and $427.6 \mathrm{~K}$ at normal pressure. Water content was $0.05 \pm 0.005 \%$ (Scheme 1 ).

- 2,4,4,6,6-pentamethyl-1,3-dioxane (3) was prepared by boiling equimolar amounts of paraldehyde (acetaldehyde polymer) and 2,4-dimethyl-2,4-pentanediol in hexane with $p$-toluenesulfonic acid as catalyst in a water entrainment unit [7]. The raw product was purified as above. The boiling point was $353 \mathrm{~K}$ at $8.6 \mathrm{kPa}$ and $423.7 \mathrm{~K}$ at normal pressure. Water content was $0.06 \pm 0.005 \%$.

- 2,2,4,4,6-pentamethyl-1,3-dioxane (4) was prepared by boiling equimolar amounts of acetone and 2-methyl-2,4-pentanediol in hexane with $p$-toluenesulfonic acid as catalyst in a water entrainment unit [7]. The raw product was purified as above. The boiling point was $420.1 \mathrm{~K}$ at normal pressure. No water was found. For NMR characterization of $\mathbf{1 - 4}$, see Refs. [5,8-11].

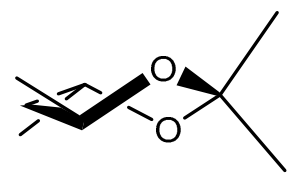

1

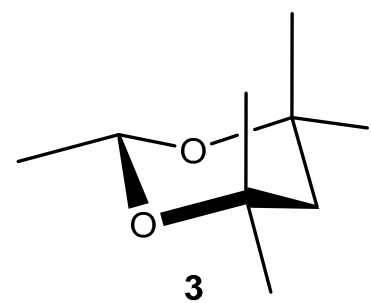

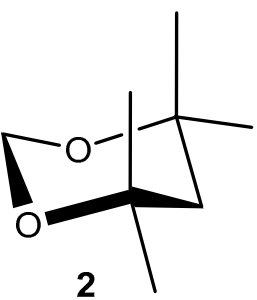

2

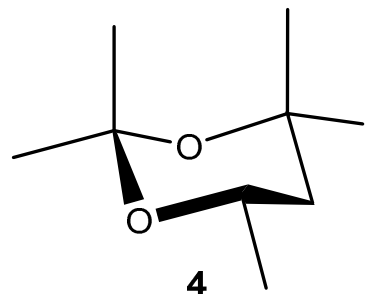

Scheme 1. Predominant conformations of 1-4. 1: 2,2-trans-4,6-dimethyl-1,3-dioxane (4,6-dipseudoequatorial 2,5-twist), 2: 4,4,6,6-tetramethyl-1,3-dioxane (chair), 3: 2,4,4,6,6-pentamethyl-1,3-dioxane (2-equatorial chair), 4: 2,2,4,4,6-pentamethyl-1,3-dioxane (6-equatorial chair) [12].

\subsection{Combustion Experiments}

The enthalpies of combustion and formation of gaseous trans-2,2,4,6-tetramethyl-1,3-dioxane (1) were published earlier [3,4]. Those of compounds 2-4 were determined as described in Materials and Methods and are listed in Tables 1-3. Table 4 in turn lists the enthalpies of formation of gaseous atoms, 
the bond energies and the bond-bond interactions [2] for the estimation of the enthalpies of formation of theoretically strain free gaseous compounds 1 to 4 shown in Scheme 1.

Table 1. Combustion results of 4,4,6,6-tetramethyl-1,3-dioxane (2, $\left.\mathrm{C}_{8} \mathrm{H}_{16} \mathrm{O}_{2}\right)$. $e^{\circ}$ (calor.) = $(10219.8 \pm 2.5) \mathrm{J} \mathrm{K}^{-1},-\Delta u_{\mathrm{c}}{ }^{\circ}$ (gel. $)=(18817.3 \pm 8.4) \mathrm{J} \mathrm{g}^{-1}, \Delta n R T=-7.4 \mathrm{~kJ} \mathrm{~mol}^{-1}$.

\begin{tabular}{|c|c|c|c|c|c|c|c|c|}
\hline \multicolumn{9}{|c|}{ Experiments ${ }^{1}$} \\
\hline & 1. & 2. & 3. & 4. & 5. & 6. & 7. & 8. \\
\hline$m(2) / g$ & 0.51757 & 0.49777 & 0.47285 & 0.53899 & 0.47061 & 0.54141 & 0.55610 & 0.53846 \\
\hline$m$ (gel.)/g & 0.12393 & 0.12088 & 0.12393 & 0.12193 & 0.12535 & 0.12237 & 0.12395 & 0.12592 \\
\hline $\begin{array}{l}e^{\mathrm{f}}(\text { cont. }) / \\
\mathrm{JK}^{-1}\end{array}$ & 17.77 & 17.62 & 17.55 & 17.85 & 17.55 & 17.85 & 17.92 & 17.85 \\
\hline $\begin{array}{l}\Delta T / \mathrm{K} \\
q(\mathrm{ign}) / \mathrm{I}\end{array}$ & $\begin{array}{c}1.9594_{4} \\
67.78\end{array}$ & $\begin{array}{c}1.8872_{2} \\
37.32\end{array}$ & $\begin{array}{c}1.8122_{2} \\
67.36\end{array}$ & $\begin{array}{c}2.0288_{8} \\
68.53\end{array}$ & $\begin{array}{c}1.8066_{6} \\
65.14\end{array}$ & $\begin{array}{c}2.0372_{2} \\
82.26\end{array}$ & $\begin{array}{c}2.0900_{0} \\
71.80\end{array}$ & $\begin{array}{c}2.0344_{4} \\
83.81\end{array}$ \\
\hline$q\left(\mathrm{HNO}_{3}\right) / \mathrm{J}$ & 32.30 & 40.58 & 40.00 & 43.30 & 38.83 & 44.22 & 44.94 & 43.47 \\
\hline$q\left(\mathrm{H}_{2} \mathrm{SO}_{4}\right) / \mathrm{J}$ & 4.06 & 3.97 & 4.06 & 4.02 & 4.14 & 4.02 & 4.06 & 4.14 \\
\hline$q($ gel. $) / J$ & 2332.04 & 2274.63 & 2332.04 & 2294.38 & 2358.73 & 2302.66 & 2332.41 & 2369.48 \\
\hline$q_{\Sigma} / \mathrm{J}$ & 7.49 & 7.20 & 6.86 & 7.78 & 6.82 & 7.82 & 8.03 & 7.78 \\
\hline $\begin{array}{l}-\Delta u_{\mathrm{c}}{ }^{\circ} / \\
\mathrm{kJg}^{-1}\end{array}$ & 34.0366 & 34.0652 & 34.0532 & 34.0508 & 34.0448 & 34.0138 & 34.0509 & 34.0216 \\
\hline $\begin{array}{l}-\Delta U_{\mathrm{c}}{ }^{\circ} / \\
\mathrm{kJmol}^{-1}\end{array}$ & 4908.5 & 4912.6 & 4910.9 & 4910.6 & 4909.7 & 4905.2 & 4910.6 & 4906.4 \\
\hline \multicolumn{9}{|c|}{ 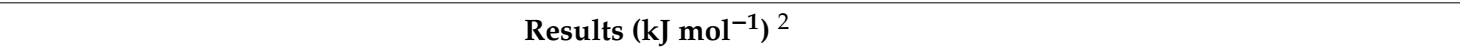 } \\
\hline$\Delta U_{\mathrm{c}}{ }^{\circ}(\mathrm{l})$ & \multirow{3}{*}{\multicolumn{2}{|c|}{$\begin{array}{c}-4909.3 \pm 2.4 \\
-4916.7 \pm 2.4 \\
-518.0 \pm 3.2\end{array}$}} & $\Delta H_{\mathrm{vap}}$ & $47.4 \pm 2$ & & & & \\
\hline$\Delta H_{\mathrm{c}}{ }^{\circ}(\mathrm{l})$ & & & $\Delta H_{\mathrm{f}}{ }^{\circ}(\mathrm{g})$ & $-470.6 \pm 4.1$ & & & & \\
\hline$\Delta H_{\mathrm{f}}^{\circ}(\mathrm{l})$ & & & & & & & & \\
\hline
\end{tabular}

Table 2. Combustion results of 2,4,4,6,6-pentamethyl-1,3-dioxane $\left(3, \mathrm{C}_{9} \mathrm{H}_{18} \mathrm{O}_{2}\right)$. $e^{\circ}$ (calor.) = $(10215.7 \pm 2.1) \mathrm{J} \mathrm{K}^{-1},-\Delta u_{\mathrm{c}}{ }^{\circ}($ gel. $)=(19440.2 \pm 6.4) \mathrm{J} \mathrm{g}^{-1}, \Delta n R T=-8.7 \mathrm{~kJ} \mathrm{~mol}^{-1}$.

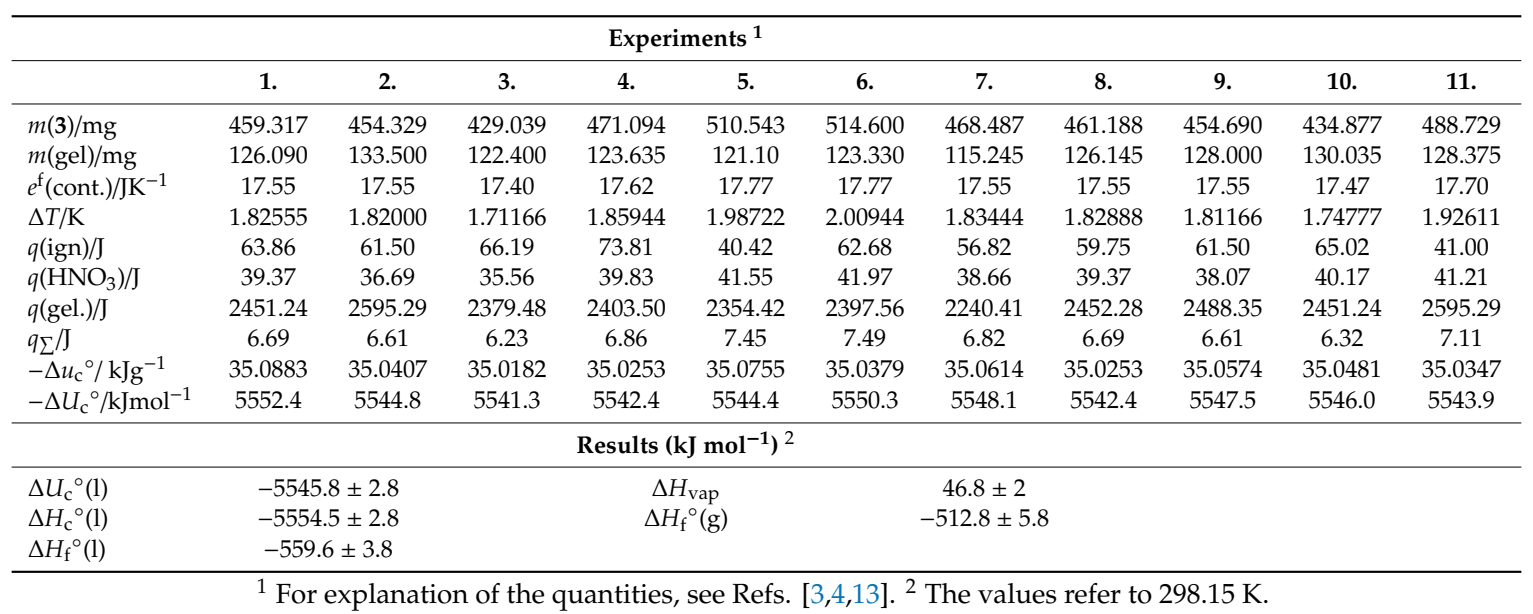

Table 3. Results of the combustions of 2,2,4,4,6-pentamethyl-1,3-dioxane $\left(4, \mathrm{C}_{9} \mathrm{H}_{18} \mathrm{O}_{2}\right) . \quad \rho(4)$ $=0.9240 \mathrm{~g} \mathrm{~cm}^{-3}, \varepsilon$ (calor) $=2261.6 \pm 0.7 \mathrm{~J}^{-1}, c_{\mathrm{p}}(4)=2.07 \mathrm{~J} \mathrm{~K}^{-1} \mathrm{~g}^{-1}, \Delta u_{\mathrm{c}}{ }^{\circ}$ (cotton fuse) $=$ $-16.240 \mathrm{~kJ} \mathrm{~g}^{-1}, \Delta u_{\mathrm{c}}{ }^{\circ}$ (polythene $)=(-46.350 \pm 0.015) \mathrm{kJ} \mathrm{g}^{-1}, \Delta n R T=-11.15 \mathrm{~kJ} \mathrm{~mol}^{-1}$.

\begin{tabular}{lccccc}
\hline \multicolumn{5}{c}{ Experiments $^{\mathbf{1}}$} \\
\hline$m(\mathbf{4}) / \mathrm{g}$ & $\mathbf{1 .}$ & $\mathbf{2 .}$ & $\mathbf{3 .}$ & $\mathbf{4 .}$ & $\mathbf{5 .}$ \\
$m($ polythene $) / \mathrm{g}$ & 0.025647 & 0.027543 & 0.035429 & 0.027748 & 0.025409 \\
$\Delta m($ cotton $) / \mathrm{g}$ & 0.020400 & 0.020750 & 0.021006 & 0.020076 & 0.021756 \\
$n^{1}\left(\mathrm{H}_{2} \mathrm{O}\right) / \mathrm{mol}$ & 0.001375 & 0.001198 & 0.001354 & 0.001452 & 0.001259 \\
\hline
\end{tabular}


Table 3. Cont.

\begin{tabular}{|c|c|c|c|c|c|}
\hline \multicolumn{6}{|c|}{ Experiments $^{1}$} \\
\hline & 1. & 2. & 3. & 4. & 5. \\
\hline$\Delta R / \Omega$ & 0.821414 & 0.857100 & 0.984095 & 0.847644 & 0.844729 \\
\hline$-\Delta R \varepsilon$ (calor.) $/ \mathrm{kJ}$ & 1.85771 & 1.93842 & 2.22563 & 1.91658 & 1.91044 \\
\hline$-\Delta T \varepsilon$ (cont.) $/ \mathrm{kJ}$ & 0.01257 & 0.01312 & 0.01506 & 0.01296 & 0.01293 \\
\hline$\Delta E$ (Wash. $) / \mathrm{kJ}$ & 0.00350 & 0.00370 & 0.00484 & 0.00378 & 0.00348 \\
\hline$\Delta E($ ign $) / \mathrm{kJ}$ & 0.00178 & 0.00125 & 0.00118 & 0.00100 & 0.00145 \\
\hline$-\Delta u_{\mathrm{c}}{ }^{\circ} / \mathrm{kJg}^{-1}$ & 34.9811 & 34.9886 & 34.9530 & 34.9813 & 35.0112 \\
\hline \multicolumn{6}{|c|}{ Results (kJ mol $\left.{ }^{-1}\right)^{2}$} \\
\hline$\Delta u_{\mathrm{c}}{ }^{\circ}(\mathrm{l})$ & $(-34.983)$ & 8) $\mathrm{kJ} \mathrm{g}^{-1}$ & $\Delta H_{\mathrm{f}}^{\circ}(\mathrm{l})$ & \multicolumn{2}{|c|}{-567.1} \\
\hline$\Delta U_{\mathrm{c}}{ }^{\circ}(\mathrm{l})$ & -55 & 2.94 & $\Delta H_{\text {vap }}$ & \multicolumn{2}{|c|}{46.2} \\
\hline$\Delta H_{\mathrm{C}}{ }^{\circ}(\mathrm{l})$ & -55 & 2.94 & $\Delta H_{\mathrm{f}}^{\circ}(\mathrm{g})$ & \multicolumn{2}{|c|}{-520.9} \\
\hline
\end{tabular}

${ }^{1}$ For explanation of the quantities, see Ref. [14]. ${ }^{2}$ The values refer to $298.15 \mathrm{~K}$.

Table 4. The values of the enthalpies of formation $\Delta H_{\mathrm{f}}{ }^{\circ}$ of gaseous atoms, the bond energies $E_{\mathrm{b}}$ and the bond-bond interactions needed to estimate the enthalpies of formation for the theoretically strain-free gaseous compounds 1 to 4 .

\begin{tabular}{|c|c|c|c|c|c|}
\hline \multicolumn{2}{|c|}{$\Delta H_{\mathrm{f}}^{\circ} / \mathrm{kJ} \mathrm{mol}^{-1}$} & \multicolumn{2}{|c|}{$E_{\mathrm{b}} / \mathrm{kJ} \mathrm{mol} \mathrm{mol}^{-1}$} & \multicolumn{2}{|c|}{ Bond-Bond Interactions/ $/ \mathrm{kJ} \mathrm{mol}^{-1}$} \\
\hline$C(g)$ & 716.7 & $\mathrm{C}-\mathrm{C}$ & 330.1 & $\Gamma_{\mathrm{CCC}}$ & 11.71 \\
\hline $\mathrm{H}(\mathrm{g})$ & 218.0 & $\mathrm{C}-\mathrm{H}$ & 415.85 & $\Gamma_{\mathrm{CCO}}$ & 24.01 \\
\hline \multirow[t]{5}{*}{$\mathrm{O}(\mathrm{g})$} & 249.2 & $\mathrm{C}-\mathrm{O}$ & 327.95 & $\Gamma_{\mathrm{COC}}$ & 23.72 \\
\hline & & & & $\Gamma_{\mathrm{OCO}}$ & 54.75 \\
\hline & & & & $\Delta_{\mathrm{CCC}}$ & -3.27 \\
\hline & & & & $\Delta_{\mathrm{CCO}}$ & -6.52 \\
\hline & & & & $\Delta_{\mathrm{OCO}}$ & -14.30 \\
\hline
\end{tabular}

\section{Discussion}

The enthalpies of vaporization of gaseous 1-4 (Scheme 1) were estimated from Equation (1) which Wadsö derived for weakly associated compounds [12]. E.g., in the case of nine gaseous secondary amines [13] the calculated enthalpies of vaporization deviated on the average from the experimental ones only by $\pm 0.5 \mathrm{~kJ} \mathrm{~mol}^{-1}$.

$$
\Delta H_{\mathrm{vap}}\left(25^{\circ} \mathrm{C}\right) / \mathrm{kJ} \mathrm{mol}^{-1}=20.9+0.172\left(t_{\mathrm{bp}} /{ }^{\circ} \mathrm{C}\right) .
$$

Compound 1: The theoretical strain-free (sf) enthalpy of formation for gaseous $\mathbf{1}$ was obtained from the following equation (the various parameters are given in Table 4):

$$
\begin{aligned}
& -\Delta H_{\mathrm{f}, \mathrm{sf}}{ }^{\circ}(\mathbf{1}, \mathrm{g})=-8 \Delta H_{\mathrm{f}}{ }^{\circ}(\mathrm{C}, \mathrm{g})-16 \Delta H_{\mathrm{f}}{ }^{\circ}(\mathrm{H}, \mathrm{g})-2 \Delta H_{\mathrm{f}}{ }^{\circ}(\mathrm{O}, \mathrm{g})+6 E_{\mathrm{b}}(\mathrm{CC})+16 E_{\mathrm{b}}(\mathrm{CH})+4 E_{\mathrm{b}}(\mathrm{CO}) \\
& +4 \Gamma_{\mathrm{CCC}}+8 \Gamma_{\mathrm{CCO}}+2 \Gamma_{\mathrm{COC}}+\Gamma_{\mathrm{OCO}}+4 \Delta_{\mathrm{CCO}}+2 \Delta_{\mathrm{OCO}} \\
& =-5733.6-3488.0-498.4+1980.6+6653.6+1311.8+46.8+192.08+47.44+54.75-26.08-28.6 \\
& =512.5 \mathrm{~kJ} \mathrm{~mol}^{-1} .
\end{aligned}
$$

The corrected experimental enthalpy of formation of liquid 1, $-526.3 \mathrm{~kJ} \mathrm{~mol}^{-1}$, was given in Ref. [4]. The enthalpy of vaporization of 1 evaluated from equation $(1)\left(t_{\mathrm{bp}}=132.2^{\circ} \mathrm{C}\right.$ ) equals $43.6 \mathrm{~kJ} \mathrm{~mol}^{-1}$ and hence $\Delta H_{\mathrm{f}}{ }^{\circ}(\mathbf{1}, \mathrm{g})=-482.7 \mathrm{~kJ} \mathrm{~mol}^{-1}$. Accordingly the value of $\Delta H_{\mathrm{CT}}(2,5)$ equals $512.5-482.7=$ $29.8 \mathrm{~kJ} \mathrm{~mol}^{-1}$ which was already quoted in Ref. [5]. 
Compounds 2 and 3 :

$$
\begin{aligned}
& -\Delta H_{\mathrm{f}, \mathrm{sf}}{ }^{\circ}(2, \mathrm{~g})=-8 \Delta H_{\mathrm{f}}{ }^{\circ}(\mathrm{C}, \mathrm{g})-16 \Delta H_{\mathrm{f}}{ }^{\circ}(\mathrm{H}, \mathrm{g})-2 \Delta H_{\mathrm{f}}{ }^{\circ}(\mathrm{O}, \mathrm{g})+6 E_{\mathrm{b}}(\mathrm{CC})+16 E_{\mathrm{b}}(\mathrm{CH})+4 E_{\mathrm{b}}(\mathrm{CO}) \\
& +7 \Gamma_{\mathrm{CCC}}+6 \Gamma_{\mathrm{CCO}}+2 \Gamma_{\mathrm{COC}}+\Gamma_{\mathrm{OCO}}+2 \Delta_{\mathrm{CCC}}+6 \Delta_{\mathrm{CCO}} \\
& =-5733.6-3488.0-498.4+1980.6+6653.6+1311.8+82.0+144.07+47.44+54.75-6.54-39.12 \\
& =508.6 \mathrm{~kJ} \mathrm{~mol}^{-1}
\end{aligned}
$$

The experimental enthalpy of formation of gaseous $2,-470.6 \mathrm{~kJ} \mathrm{~mol}^{-1}$, is given in Table 1 . Thus, the total strain in 2 is $508.6-470.6=38.0 \mathrm{~kJ} \mathrm{~mol}^{-1}$. This is including two $2-\mathrm{H}_{\mathrm{ax}}, 4-\mathrm{Me}_{\mathrm{ax}}$ interactions [4] $\left(17.0 \mathrm{~kJ} \mathrm{~mol}^{-1}\right)$ together with the syn-axial 4,6-Me,Me interaction. Accordingly, the latter is equal to $38.0-17.0=21.0 \mathrm{~kJ} \mathrm{~mol}^{-1}$.

Similarly:

$$
\begin{aligned}
& -\Delta H_{\mathrm{f}, \mathrm{sf}}{ }^{\circ}(3, \mathrm{~g})=-9 \Delta H_{\mathrm{f}}{ }^{\circ}(\mathrm{C}, \mathrm{g})-18 \Delta H_{\mathrm{f}}{ }^{\circ}(\mathrm{H}, \mathrm{g})-2 \Delta H_{\mathrm{f}}{ }^{\circ}(\mathrm{O}, \mathrm{g})+7 E_{\mathrm{b}}(\mathrm{CC})+18 E_{\mathrm{b}}(\mathrm{CH})+4 E_{\mathrm{b}}(\mathrm{CO}) \\
& +7 \Gamma_{\mathrm{CCC}}+8 \Gamma_{\mathrm{CCO}}+2 \Gamma_{\mathrm{COC}}+\Gamma_{\mathrm{OCO}}+2 \Delta_{\mathrm{CCC}}+6 \Delta_{\mathrm{CCO}}+\Delta_{\mathrm{OCO}} \\
& =-6450.3-3924.0-498.4+2310.7+7485.3+1311.8+82.0+192.08+47.44+54.75-6.54-39.12-14.3 \\
& =551.4 \mathrm{~kJ} \mathrm{~mol}^{-1}
\end{aligned}
$$

The evaluated enthalpy of gaseous $3,-512.8 \mathrm{~kJ} \mathrm{~mol}^{-1}$, is given in Table 2. Thus the total strain in 3 is $551.4-512.8=38.6 \mathrm{~kJ} \mathrm{~mol}^{-1}$. This includes again two $2-\mathrm{H}_{\mathrm{ax}}, 4-\mathrm{Me}_{\mathrm{ax}}$ interactions [4] $\left(17.0 \mathrm{~kJ} \mathrm{~mol}^{-1}\right)$ together with the syn-axial 4,6-Me,Me interaction. Accordingly, the latter equals $38.6-17.0=21.6 \mathrm{~kJ} \mathrm{~mol}^{-1}$. So on the average 4,6-diaxial Me,Me-interaction equals $21.3 \mathrm{~kJ} \mathrm{~mol}^{-1}$.

In order to determine syn-axial 2,4-Me,Me-interaction we must evaluate the theoretical enthalpy of formation for the strain-free gaseous 4 :

$$
\begin{aligned}
& -\Delta H_{\mathrm{f}, \mathrm{sf}}{ }^{\circ}(4, \mathrm{~g})=-9 \Delta H_{\mathrm{f}}{ }^{\circ}(\mathrm{C}, \mathrm{g})-18 \Delta H_{\mathrm{f}}{ }^{\circ}(\mathrm{H}, \mathrm{g})-2 \Delta H_{\mathrm{f}}{ }^{\circ}(\mathrm{O}, \mathrm{g})+7 E_{\mathrm{b}}(\mathrm{CC})+18 E_{\mathrm{b}}(\mathrm{CH})+4 E_{\mathrm{b}}(\mathrm{CO}) \\
& +6 \Gamma_{\mathrm{CCC}}+9 \Gamma_{\mathrm{CCO}}+2 \Gamma_{\mathrm{COC}}+\Gamma_{\mathrm{OCO}}+\Delta_{\mathrm{CCC}}+6 \Delta_{\mathrm{CCO}}+2 \Delta_{\mathrm{OCO}} \\
& =-6450.3-3924.0-498.4+2310.7+7485.3+1311.8+70.3+216.1+47.44+54.75-3.27-39.12-28.6 \\
& =552.6 \mathrm{~kJ} \mathrm{~mol}^{-1}
\end{aligned}
$$

The experimental enthalpy of formation of gaseous $4,-520.9 \mathrm{~kJ} \mathrm{~mol}^{-1}$, is given in Table 3. Accordingly, the total interactions in 4 are $552.6-520.9=31.7 \mathrm{~kJ} \mathrm{~mol}^{-1}$. This includes one 2- $\mathrm{Me}_{\mathrm{ax}}, 6-\mathrm{H}_{\mathrm{ax}}$ [4], one 4- $\mathrm{Me}_{\mathrm{ax}}, 6-\mathrm{H}_{\mathrm{ax}}$ interaction [4], i.e., $8.5+3.7=12.2 \mathrm{~kJ} \mathrm{~mol}^{-1}$. Thus the magnitude of 2,4-diaxial Me,Me-interaction is equal to $31.7-12.2=19.5 \mathrm{~kJ} \mathrm{~mol}^{-1}$. In other words the syn-axial $\mathrm{Me}, \mathrm{Me}$-interactions do not differ too much from each other but appear to indicate that the chair form of 4 can be somewhat more deformed than those of 2 and 3 . If compound $\mathbf{1}$ would exist also in the chair form its total strain should be practically equal to that, $31.7 \mathrm{~kJ} \mathrm{~mol}^{-1}$, in 4 . However, it is only $29.8 \mathrm{~kJ} \mathrm{~mol}^{-1}$ which supports its existence in the 2,5-twist form.

\section{Materials and Methods}

The standard enthalpy of combustion of 2,2,4,4,6-pentamethyl-1,3-dioxane (4) was determined on the high-precision aneroid static-bomb combustion calorimeter built and tested in Stirling. The detailed structure and procedure were as described earlier [14]. The standard enthalpies of combustion of 4,4,6,6-tetra- (2) and 2,4,4,6,6-pentamethyl-1,3-dioxanes (3) were in turn determined by burning them in oxygen in an adiabatic bomb calorimeter No. 1221 manufactured by Parr instruments Co., Illinois, USA. The bomb and procedure were described earlier as well $[3,4]$.

Author Contributions: Professor K.P. supervised the work and carried out the calculations and wrote the paper together with Dr. H.K. Drs. P.V. (compounds 2 and 3) and W.V.S. (compound 4) determined the enthalpies of combustion. Syntheses were carried out by Dr. P.V. and Prof. K.P.'s technician Markku Kivimäki. All authors have read and agreed to the published version of the manuscript.

Funding: This research received no external funding.

Conflicts of Interest: The authors declare no conflicts of interest. 


\section{References}

1. Pihlaja, K.; Kleinpeter, E. Carbon-13 NMR Chemical Shifts in Structural and Stereochemical Analysis; Wiley-VCH: New York, NY, USA, 1994.

2. Pihlaja, K.; Rossi, K.; Vainiotalo, P. Bond-bond interactions in alkanes and their hetero analogs. Allen-type group increments for estimating enthalpies of formation of alkanes and their oxygen, sulfur, and nitrogen analogs and aliphatic ketones. J. Chem. Eng. Data 1985, 30, 387-394. [CrossRef]

3. Pihlaja, K.; Heikkilä, J. Heats of Combustion of 1,3-Dioxane and Its Methyl Derivatives. Acta Chem. Scand. 1967, 21, 2390-2398. [CrossRef]

4. Pihlaja, K.; Luoma, S. Heats of Formation and Conformational Energies of 1,3-Dioxane and Its Methyl Homologues. Acta Chem. Scand. 1968, 22, 2401-2414. [CrossRef]

5. Pihlaja, K.; Kivimäki, M.; Myllyniemi, A.M.; Nurmi, T. Carbon-13 chemical shifts: Sensitive detectors in structure determination. Part 2. Carbon-13 nuclear magnetic resonance chemical shifts and the twist conformations of 1,3-dioxanes. Geminal substitution at the 4-position: A guaranty for the chair form? J. Org. Chem. 1982, 47, 4688-4692. [CrossRef]

6. Pihlaja, K.; Ketola, M. Preparation of 1,3-Propanediol and Its Methyl Derivatives by Grignard Reactions or by $\mathrm{LiAlH}_{4}$ Reduction. Acta Chem. Scand. 1969, 23, 715-726. [CrossRef]

7. Rondestvedt, C.S. m-Dioxanes and Other Cyclic Acetals. J. Org. Chem. 1961, 26, 2247-2253. [CrossRef]

8. Pihlaja, K.; Nurmi, T. ${ }^{13} \mathrm{C}$ Chemical Shifts - Sensitive Detectors in Structure Determination. ${ }^{13} \mathrm{C}$ NMR Studies of Saturated Heterocycles. Methyl-Substituted 1,3-Dioxanes. Israel J. Chem. 1980, 20, 160-167. [CrossRef]

9. Kellie, G.M.; Riddell, F.G. The Carbon-13 Nuclear Magnetic Resonance Spectra of Some 1,3-Dioxans. Part II. A Demonstration of Non-chair Conformations. J. Chem. Soc. B 1971, 1030-1034. [CrossRef]

10. Pihlaja, K.; Äyräs, P. Conformational Analysis. NMR Spectra of Six-Membered Cyclic Acetals. Acta Chem. Scand. 1970, 24, 531-549. [CrossRef]

11. Samitov, Y.Y.; Yuldasheva, L.K.; Anonimova, I.V. Proton and carbon-13 NMR spectra, dipole moments, and conformations of six-member 4,4,6,6-tetramethyl-1,3-dioxa-2-hetero(sulfur, selenium, arsenic) cycles. Zh. Org. Khim. 1982, 18, 406-415.

12. Wadsö, I. Heats of Vaporization for a Number of Organic Compounds at 25 degrees C. Acta Chem. Scand. 1966, 20, 544-552. [CrossRef]

13. Vainiotalo, P. Measurements and Calculations Concerning Energetic Factors Present in Alkanes and Their Heteroanalogues Utilizing Bond-Bond Intereraction Schemes. Bachelor Thesis, University of Turku, Turku, Finland, 1980. (In Finnish).

14. Parker, W.; Steele, W.; Stirling, W.; Watt, I. A high-precision aneroid static-bomb combustion calorimeter for samples of about $20 \mathrm{mg}$. The standard enthalpy of formation of bicyclo[3.3.3]undecane. J. Chem. Thermodyn. 1975, 7, 795-802. [CrossRef]

Sample Availability: Samples of the compounds are not available from the authors.

(C) 2020 by the authors. Licensee MDPI, Basel, Switzerland. This article is an open access article distributed under the terms and conditions of the Creative Commons Attribution (CC BY) license (http://creativecommons.org/licenses/by/4.0/). 